Publicação organizada pelo Programa de

Mestrado Profissional Stricto Sensu em

Engenharia Civil da Universidade São Judas

Volume 03 - Edição 01

Janeiro - Dezembro de 2020

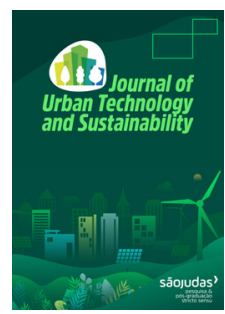

\title{
A produção habitacional do programa MCMV no município de São Paulo: critérios de localização adotados pelos produtores e impactos na estrutura urbana e na qualidade de vida dos moradores
}

\author{
Edson L. Ribeiroa,", José A. R. Silveirab \\ ${ }^{a}$ Engenharia Urbana - Secretaria Nacional da Habitação - SNH/ MDR, Brasília, Brasil. \\ ${ }^{b}$ Programa de Pos-Graduação em Arquitetura e Urbanismo - LAURBE / PPGAU - CT - Universidade Federal da Paraíba, João Pessoa, Brasil.
}

Informações

Recebido 8 Outubro 2020

Manuscrito revisado recebido

18 Novembro 2020

Aceito 28 Novembro 2020

Palavras-chave

Minha Casa, Minha Vida

Estrutura urbana

Qualidade de vida

\section{Resumo}

O estudo avalia a concentração da produção habitacional do Programa Minha Casa, Minha Vida no município de São Paulo em suas várias faixas de renda familiar, estudando-se a sua relação particularmente aos seguintes aspectos: a) distância do centro tradicional; b) distância dos novos centros geradores de emprego; c) oferta local de oportunidades de trabalho e renda e d) índice de violência urbana, comparando-se ainda com resultados de outra pesquisa sobre a satisfação com a qualidade de vida urbana por setor urbano na cidade. Embora tenha ficado clara a correlação inversa entre a concentração local da produção habitacional em relação à proximidade das oportunidades de trabalho e renda, outros índices comparados não apresentaram os mesmos resultados. Também ficou constatado que, no âmbito do município, a produção longínqua dos conjuntos habitacionais não produziu significativa dispersão urbana, tendo os mesmos, em função do uso da verticalização, ocupado predominantemente terrenos e glebas intersticiais (vazios urbanos).

\section{Housing production in the MCMV program in the city of São Paulo: location criteria adopted by contractors and impacts on urban structure and quality of life for residents}

\section{Article info \\ Received 8 Octubre 2020 \\ Received in revised form 19 November 2020 \\ Accepted 28 November \\ 2020 \\ Keywords \\ Minha Casa, Minha Vida \\ Urban structure \\ Quality of life}

\begin{abstract}
The study assesses the concentration of housing production of the Minha Casa, Minha Vida Program in the municipality of São Paulo in its various ranges of family income, studying its relationship particularly with the following aspects: a) distance from the traditional center; b) distance from new job-generating centers; c) local offer of job and income opportunities and d) urban violence index, comparing with results of another survey on satisfaction with the quality of urban life by urban sector in the city. Although it was clear the inverse correlation between the local concentration of housing production in relation to the proximity of work and income opportunities, other compared indexes did not show the same results. It was also found that, within the scope of the municipality, the distant production of the housing complexes did not produce significant urban dispersion, having, due to the use of verticalization, occupied predominantly land and interstitial plots (urban voids).
\end{abstract}

\section{Producción de vivienda en el programa MCMV en la ciudad de São Paulo: criterios de ubicación adoptados por constructores e impactos en la estructura urbana y calidad de vida de los residentes}

\section{Información}

Recibido 8 Octubre 2020

Manuscrito revisado recibido

19 Noviembre 2020

Aceptado 28 Noviembre

Palabras clave

Minha Casa, Minha Vida

Estructura urbana

Calidad de vida

\section{Resumen}

El estudio evalúa la concentración de la producción habitacional del Programa Minha Casa, Minha Vida en el municipio de São Paulo en sus diversos rangos de ingresos familiares, estudiando su relación particularmente con los siguientes aspectos: a) distancia del centro tradicional; b) distancia de nuevos centros generadores de empleo; c) oferta local de oportunidades laborales y de ingresos y d) índice de violencia urbana, comparándolo con los resultados de otra encuesta sobre satisfacción con la calidad de vida urbana por sector urbano de la ciudad. Si bien quedó clara la correlación inversa entre la concentración local de la producción de vivienda en relación con la proximidad de oportunidades laborales y de ingresos, otros índices comparados no alcanzaron mismos resultados. También se encontró que, en el ámbito del municipio, la producción distante de los conjuntos habitacionales no produjo una dispersión urbana significativa, habiendo, debido al uso de la verticalización, ocupado predominantemente terrenos y solares intersticiales (vacíos urbanos).

\footnotetext{
* Autor correspondente em: Secretaria Nacional da Habitação - SNH/ MDR.

E-mail: edlribeiro@gmail.com (Edson L. Ribeiro)
}

https://doi.org/10.47842/juts.v3i1.25

ISSN: 2675-780X 


\section{Introdução}

Em uma análise bastante recente da política habitacional estatal no Brasil, verifica-se que desde a incapacidade do Sistema Financeiro da Habitação-SFH de atender a provisão habitacional na faixa de renda mais crítica e, a partir dos anos 1980, com o colapso do SFH e a descontinuidade na produção e oferta de habitação popular, associado ainda com o aumento da pressão populacional no centro urbano, observou-se que o processo de favelização, ocupações informais, inclusive em áreas de risco continuou a aumentar nas grandes cidades. No período da segunda metade da década de 1980 até a passagem do século, a produção habitacional social formal esteve quase que limitada aos segmentos de renda intermediaria, devido à pouca iniciativa direta do governo federal no período, sendo caracterizada por um período de intensificação da produção informal, em áreas ocupadas ou em loteamentos periféricos.

Em 2001, foi promulgado o Estatuto da Cidade, que é resultado da luta árdua dos movimentos de reforma urbana e de lutas pela moradia. Nesta lei, se consagra o conceito do direito à cidade e da submissão do direito de propriedade à sua função social. Em 2003, foi criado o Ministério das Cidades, com a proposta de uma visão ampliada e integrada sobre as questões urbanas, onde já viviam mais de $80 \%$ da população nacional. Além do seu aspecto técnico-institucional, a proposta de funcionamento de um sistema colegiado, representado pelo Conselho das Cidades, com competência propositiva para as ações desse Ministério, também pode ser entendido como um avanço positivo em uma forma mais participativa de gestão, apesar das dificuldades inerentes a esse funcionamento.

Em 2004, foi aprovada a Política Nacional de Habitação-PNH e, a partir de seus princípios, foi concebido o Sistema Nacional de Habitação e, dentre esse, especialmente o Sistema Nacional de Habitação de Interesse Social-SNHIS, criado pela lei $11124 / 2005$. No funcionamento do SNHIS se previa o pacto federativo, e o compromisso pelos entes que aderissem nos três níveis (união, estados e municípios), em garantir um Fundo de Habitação, um Conselho Gestor do Fundo de Habitação e elaborar e obedecer a um Plano de Habitação. Esse funcionamento estimularia a cooperação federativa, a cultura da participação (através dos Conselhos) e a cultura do Planejamento, pela obrigatoriedade do Plano. Além disso, seus objetivos principais era o atendimento de provimento habitacional para as faixas de renda mais representativas no déficit habitacional, à época, considerada as faixas de renda de até três salários-mínimos. Também eram previstas no programa, ações de urbanização de favelas e de assistência técnica. Seu funcionamento, apesar de lento e não conseguir atingir a todos os municípios mais carentes, se caracterizava por um avanço considerado na condução democrática e técnica do problema de habitação, especialmente para as faixas de renda mais baixa e com menor acessibilidade à habitação digna.

\section{O Programa MCMV}

Com o advento da crise econômica mundial de 2008 e 2009, foi lançado o programa Minha Casa, Minha Vida, que visava, simultaneamente, reduzir o déficit quantitativo habitacional e dinamizar a economia, gerando empregos e renda, através da atividade de construção de habitação de interesse social. Tal programa visava atingir todo o espectro da chamada faixa de habitação social. Dessa forma, tinha algumas variantes, chamadas comumente de faixas 1, 2 e 3, onde a chamada faixa 1 era a faixa mais crítica (0 a 3 Salários mínimos) e tinham subsídios mais significativos, garantidos pelo Fundo de Arrendamento Residencial (FAR): seu pagamento mensal era limitado a um pequeno percentual da renda mensal, tendo seus resíduos cobertos por Fundo garantidor. Nessa faixa, o beneficiário não escolhe o imóvel, mas o mesmo é sorteado entre os inscritos que atendem as condições exigidas.

A chamada faixa 2, utilizando-se recursos do FGTS teria um pequeno subsídio fixo, juros mais baixos e o Fundo Garantidor ofereceria certa segurança quanto a eventos de desemprego ou renda cessante; e a Faixa 3, com recursos do FGTS onde não haveria subsídios, apenas melhores garantias e juros menos onerosos.

Por questões de limitação orçamentaria e por 
vontade política de reforçar a validade do Programa Minha Casa, Minha Vida, já consagrado pela sua grande capacidade de produção quantitativa de unidades habitacionais, o SNHIS, apesar de este dever ser o Sistema mais permanente e estruturante, foi gradativamente legado a um segundo plano e, posteriormente, quase esquecido, especialmente nas ações de provimento habitacional. Além disso, deve ser destacado que o SNHIS tinha sido criado e colocado em prática como resposta às reivindicações históricas dos movimentos sociais.

Em relação ao aspecto quantitativo de sua produção, não há dúvidas que sua contribuição foi bastante eficiente, ultrapassando todos os períodos anteriores, inclusive a produção considerável no SFH, durante o período do governo militar que segundo Arretche apud Dutra (2012) atingiu 4.300.000 unidades habitacionais no país. Observando ainda que nesses programas anteriores, as faixas de baixíssima renda (equivalente a faixa 1) eram pouco atingidas.

\section{A produção habitacional através do MCMV em São Paulo - SP}

A produção habitacional, pelo MCMV em suas várias etapas, de 2009 a 2015, no município de São Paulo - SP, também se caracterizou pela grande quantidade de unidades habitacionais produzidas, como pode ser observado na síntese a seguir:

Igualmente ao observado nos programas do governo militar, com o foco na casa própria, esse programa provia um bem privado, e não exatamente um serviço público. E da mesma forma, sua lógica seguia a regra de mercado: mantinhase o lucro dos produtores reduzindo-se os custos, com prejuízos notáveis na qualidade habitacional e na inserção urbana. Apesar do grande êxito quantitativo do programa, o que em princípio é positivo, tendo em vista a magnitude do déficit quantitativo brasileiro, ele recebeu várias críticas em relação ao seu aspecto qualitativo, tanto no aspecto da unidade habitacional, quanto dos conjuntos e empreendimentos e, especialmente no que diz respeito à sua inserção urbana.

Temporalmente, o número de contratação e execução dessas unidades habitacionais, no município considerado, teve seus picos de produção habitacional nos anos 2010 e 2014. Observou-se também que, no município, a produção destinada às faixas 2 e 3 foi maior que a destinada à faixa 1 , considerada a mais crítica no déficit habitacional. De forma geral a produção habitacional na faixa 2 predominou sobre a faixa 1 em todos os anos. No caso da faixa 3, apenas os resultados de 2013, 2014 e 2015 não foram maiores que os da faixa 1. Ver tabela 3.

No caso de São Paulo, como em todas as metrópoles e cidades de médio e grande porte no Brasil, também se observou tal fenômeno. Os empreendedores do Programa mantinham seus lucros pretendidos buscando reduzir os seus custos. Dentre as providências neste sentido, especialmente foi utilizada a redução dos custos de aquisição da terra.

Observando-se inicialmente os bairros de maior implantação de empreendimentos e os fatores

Tabela 1. Unidades habitacionais contratadas através do Programa MCMV no Brasil entre 2009 e 2016 (CAIXA, 2017$).$

\begin{tabular}{ccccccccc}
\hline Modalidade & $\mathbf{2 0 0 9}$ & $\mathbf{2 0 1 0}$ & $\mathbf{2 0 1 1}$ & $\mathbf{2 0 1 2}$ & $\mathbf{2 0 1 3}$ & $\mathbf{2 0 1 4}$ & $\mathbf{2 0 1 5}$ & $\mathbf{2 0 1 6}$ \\
\hline Faixa 1 & 143894 & 338847 & 104311 & 389073 & 557961 & 175260 & 16890 & 27968 \\
Empresas & 143484 & 260644 & 83358 & 306847 & 419940 & 106670 & 1188 & 1738 \\
Rural & 101 & 5716 & 12295 & 41124 & 56899 & 48921 & 9064 & 15411 \\
Urbana & 309 & 7715 & 2988 & 7751 & 16382 & 18737 & 6064 \\
Cid < 50 & 0 & 63722 & 5670 & 32751 & 64740 & 0 & 10819 \\
Faixa 2 & 98593 & 277171 & 325953 & 311965 & 288708 & 289715 & 344729 & 144560 \\
Faixa 3 & 43818 & 102805 & 77935 & 97711 & 93799 & 37609 & 40526 & 29595 \\
Total p/ ano & 286305 & 718823 & 508199 & 798747 & 940468 & 502584 & 402145 & 202123 \\
\hline
\end{tabular}

TOTAL 2009-2016: 4359394 
Tabela 2. Unidades habitacionais contratadas e concluídas, por modalidade, no município de São Paulo/SP entre 2009 e 2015 (SISHAB/SNH, 2019).

\begin{tabular}{|c|c|c|c|}
\hline Modalidade & $\begin{array}{l}\text { Faixa } \\
\text { renda }\end{array}$ & Contratadas & Concluídas \\
\hline Entidades & Faixa 1 & 7000 & 3192 \\
\hline FAR - Empresas & Faixa 1 & 7168 & 780 \\
\hline $\begin{array}{l}\text { FAR Urbanização } \\
\text { (vinculadas) }\end{array}$ & Faixa 1 & 5528 & 280 \\
\hline \multicolumn{2}{|c|}{ Total Faixa 1} & 19696 & 4252 \\
\hline CCFGTS & Faixa 2 & 34232 & 32507 \\
\hline CCFGTS & Faixa 3 & 25707 & 21239 \\
\hline \multicolumn{2}{|l|}{ TOTAL } & 79635 & 63126 \\
\hline
\end{tabular}

mais diretamente relacionados com a (des) valorização do solo urbano local, conjeturouse que, dentre os locais mais utilizados para a construção dos mesmos, em função dos custos estariam basicamente os seguintes: a) terrenos mais distantes do centro urbano e áreas de oferta de oportunidades; b) terrenos localizados em áreas de baixa oferta local de oportunidades de trabalho, emprego e renda e c) terrenos localizados em áreas de maiores índices de violência urbana.

Dessa maneira, entre os empreendimentos executados no município de São Paulo, foram testadas essas três condições, com forte capacidade de influir negativamente no valor do imóvel, tornando-os mais "atrativos" para os empreendedores.

\section{Metodologia}

Como metodologia se buscou avaliar a relação que havia entre as áreas de maior produção de unidades habitacionais no município e as citadas condições: 1) valor do solo; 2) distância do centro; 3) oferta local de oportunidades e 4) índice de violência). Para o critério "distância do centro", se dividiu a produção habitacional por faixas de distância (0 a 5, 5 a 10 km....) do centro urbano tradicional (a partir do Vale do Anhangabaú). Foi também utilizado o critério de distância em relação ao novo centro de tendência de oferta de oportunidades de trabalho mais bem remunerado (tomando-se como referência o quadrilátero: Berrini - Faria Lima), considerado o novo centro "pósmoderno" da cidade, em função de sua crescente capacidade de geração de oportunidades.

Para o critério da oferta local de oportunidades de trabalho, emprego e renda, se correlacionou a produção habitacional relativa por bairro (\% em relação à produção total) e a oferta relativa de postos de trabalho por bairro (\% da oferta em relação à oferta total no município). E, finalmente, em relação ao aspecto da violência urbana, adotouse o critério universal da taxa de homicídios (no. de homicídios/100.000 habitantes) por bairro e a sua relação com a produção e oferta de unidades habitacionais no MCMV. Tais resultados também foram relacionados com aspectos da estrutura urbana, tal como a dispersão territorial e a percepção coletiva da qualidade de vida urbana por setor urbano.

\section{Resultados obtidos}

De maneira geral, os setores que mais receberam unidades habitacionais do Programa Minha Casa, Minha Vida na cidade foram os setores leste, norte e sul, notadamente em suas áreas mais distantes e caracterizadas pela ocupação predominante de populações de baixa renda.

O setor da cidade que mais recebeu unidades habitacionais do programa foi o setor Leste $(56,81 \%)$, seguido do setor Norte $(20,34 \%)$ e o setor Sul (13,07\%) que, apesar de sua diversidade tipológica, constituem zonas urbanas com

Tabela 3. Unidades habitacionais contratadas por faixa de renda (todas as modalidades) e por ano no município de São PauloSP entre 2009 e 2015 (GI/SNH, 2018).

\begin{tabular}{lccccccc}
\hline Faixa & $\mathbf{2 0 0 9}$ & $\mathbf{2 0 1 0}$ & $\mathbf{2 0 1 1}$ & $\mathbf{2 0 1 2}$ & $\mathbf{2 0 1 3}$ & $\mathbf{2 0 1 4}$ & $\mathbf{2 0 1 5}$ \\
\hline Faixa 1 & 680 & 4868 & 500 & 2432 & 3612 & 4754 & 2850 \\
Faixa 2 & 4375 & 7130 & 4608 & 2932 & 4683 & 4819 & 5685 \\
Faixa 3 & 5269 & 6733 & 4995 & 3593 & 2159 & 2112 & 846 \\
\hline
\end{tabular}




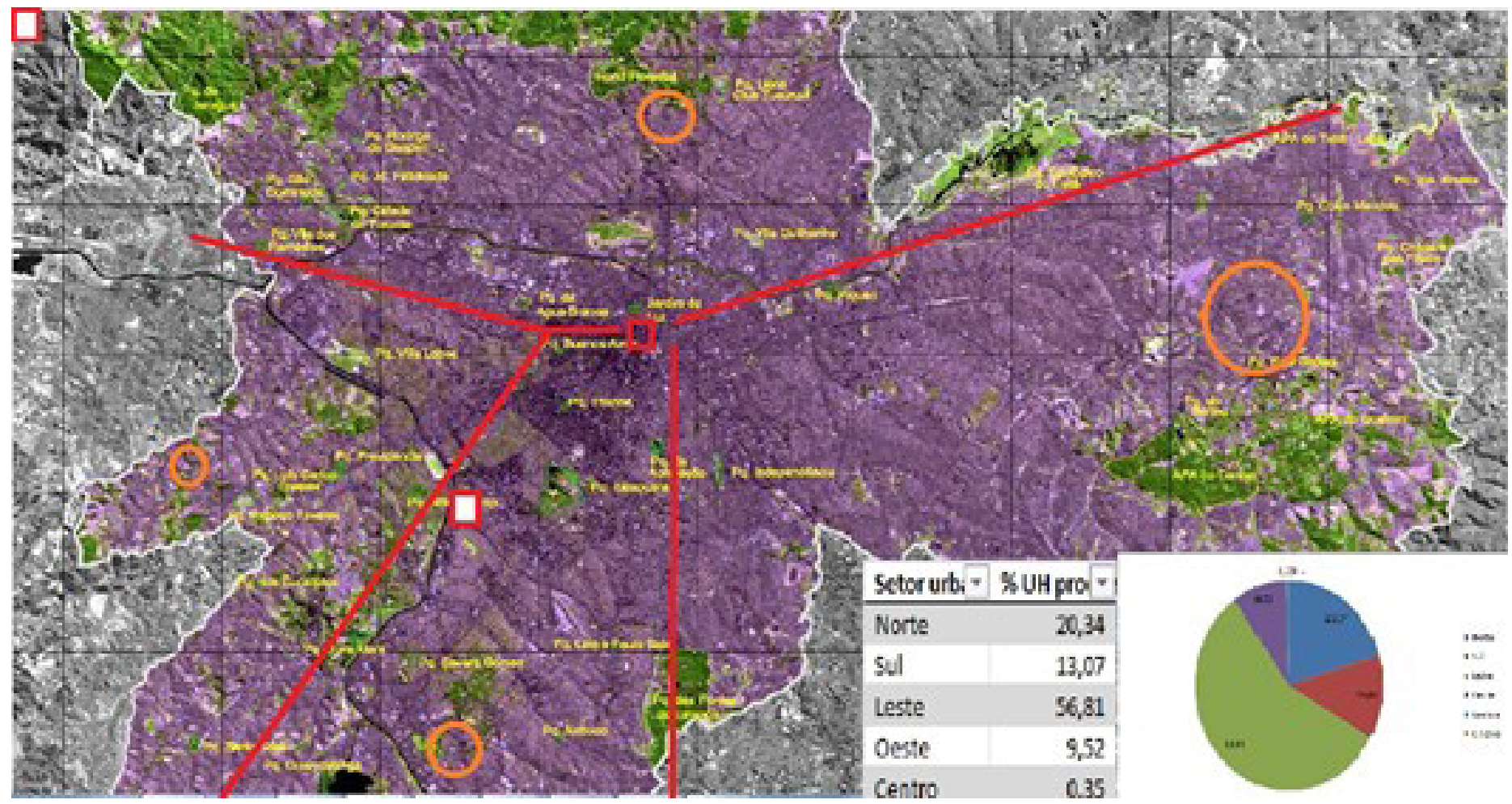

Fig. 1. Proporção da produção de unidades habitacionais no MCMV por setor urbano do município de São Paulo - SP (adaptado de Atlas Ambiental PMSP, 2019).

predominância de habitações populares. Pode ser observado que entre estes setores urbanos, a área Leste, exatamente a mais distante dos centros concentrou maior número de UH produzidas. O setor Oeste, mais próximo das áreas mais geradoras de emprego e renda e, portanto, com solo um pouco mais caro, teve participação relativamente modesta (9,52\%). Mas, foi o setor central, com apenas 0,35\% das UH implantadas que representou o setor menos utilizado para esse fim, o que representa uma anomalia e um prejuízo claro à harmonia estrutural, funcional e social da cidade, uma vez que este representa uma área de grande oferta oportunidades de trabalho e de bens e serviços públicos e privados, constituindo-se portanto uma das áreas de maior qualidade para a habitação.

\section{a. Distâncias em relação aos setores urbanos maiores geradores de oportunidades de trabalho e renda}

Tomando-se inicialmente o critério de distância do centro tradicional e também a distância das novas áreas de geração de emprego e renda (setor sudoeste da área pericentral), observou-se o seguinte resultado: A produção de UH pelo MCMV foi relativamente pequena nas faixas de até $10 \mathrm{~km}$ em relação ao centro tradicional, notadamente na faixa entre 0 e $5 \mathrm{~km}$. A faixa de maior produção foi entre 16 e $20 \mathrm{~km}$, voltando a diminuir na faixa entre 21 e 25 km. Provavelmente essa redução está mais em função de certa inviabilidade mercadológica, especialmente para as faixas 2 e 3 , cujos picos ocorreram respectivamente na faixa $16-20 \mathrm{~km}$ e 11-15 km. Nota-se, no entanto que, para a faixa 1, exatamente a que se refere a famílias com menores recursos de mobilidade, a produção foi crescente à medida da distância do centro, atingindo o seu pico exatamente na faixa mais distante. Uma das poucas facilidades para os residentes na faixa mais distante do centro principal e também dos centros secundários, notadamente o da zona Leste da cidade, é a possibilidade de utilizar-se da rede ferroviária, presente nesse setor urbano, quando a localização do conjunto habitacional assim o permitir, ou ainda acessar áreas geradoras de emprego também em municípios vizinhos.

Em relação ao novo centro de Iocalização empresarial, notadamente um polo gerador de empregos mais bem remunerados, que é o setor pericentral sudoeste, também se observou um 
Tabela 4. Unidades habitacionais produzidas no MCMV, por faixa de renda e por faixa de distância em relação ao centro urbano tradicional (adaptado de GI-SNH, 2018).

\begin{tabular}{ccccccc}
\hline Faixa / Distância & Até $\mathbf{5 ~} \mathbf{~ m}$ & $\mathbf{6}$ a $\mathbf{1 0} \mathbf{~ k m}$ & $\mathbf{1 1} \mathbf{~ 1 5} \mathbf{~ k m}$ & $\mathbf{1 6}$ a $\mathbf{2 0} \mathbf{~ k m}$ & $\mathbf{2 1} \mathbf{a} \mathbf{2 5} \mathbf{~ k m}$ & Total \\
\hline MCMV - faixa 1 & 0 & 140 & 592 & 3244 & 3502 & 7478 \\
MCMV - faixa 2 & 1469 & 1381 & 4582 & 4842 & 1938 & 12274 \\
MCMV - faixa 3 & 40 & 2483 & 4620 & 4588 & 2286 & 14017 \\
Total & 1509 & 4364 & 9794 & 12.674 & 7286 & 40308 \\
\hline
\end{tabular}

comportamento semelhante. Com pequenos percentuais de localização das UH na faixa até 10 $\mathrm{km}$, o pico das faixas 2 e 3 encontra-se no intervalo de 16 a 20 km de distância. Na faixa 1, no entanto, observa-se o pico, além de um crescimento forte, na faixa além dos $20 \mathrm{~km}$ de distância. Nessa avaliação, percebe-se que a distância média para as UH localizadas no setor leste e setor norte da cidade, aumentou, tornando essas localizações menos favoráveis. No caso do setor norte, ainda menos favorável por não poder contar com uma rede ferroviária ou metroviária que a interligue diretamente, à exceção de sua parte mais a oeste. No caso da faixa de renda 1, pela baixa escolaridade e capacitação técnica, esse centro não representa um setor de grande oferta de oportunidades de trabalho, sendo mais importante a oferta local de empregos (no próprio bairro ou setor urbano) e no centro tradicional, para o qual os sistemas de transporte coletivo convergem com mais facilidade.

Ressalta-se também que, com o deslocamento das atividades econômicas mais rentáveis para o setor sudoeste, devido à grande assimetria social urbana, as regiões Leste e Norte, exatamente as que mais produziram no Programa, ficaram mais

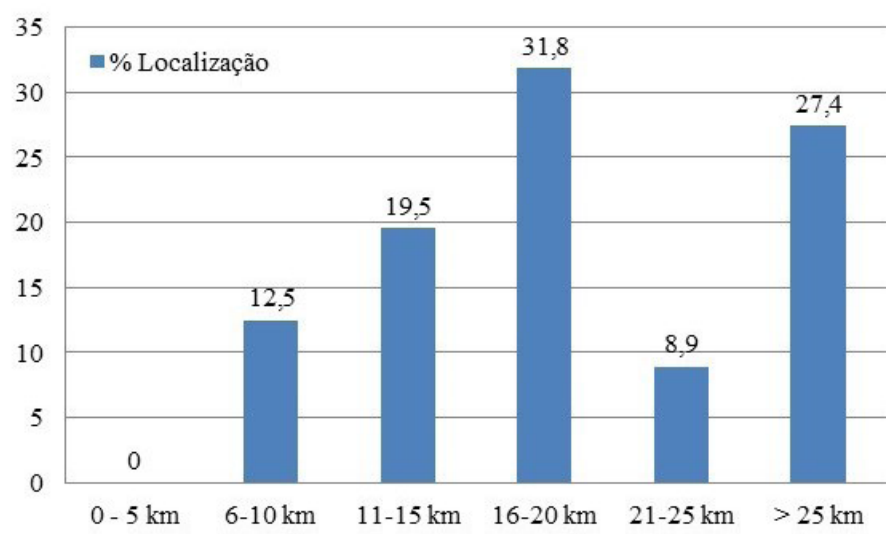

Fig. 2. Números percentuais da produção de UH-MCMV por faixa de distância entre os conjuntos habitacionais e o novo centro gerador de empregos em São Paulo/SP (adaptado de GI-SNH, 2018). distanciadas e prejudicadas, tanto do ponto de vista da distância, quanto do ponto de vista das alternativas e facilidades em transportes coletivos.

Em estudos como o de Linke et al. (2016), verificouse que, em princípio, nos conjuntos habitacionais implantados até $20 \mathrm{~km}$ de distância dos centros considerados, apesar da distância às melhores ofertas de trabalho, os conjuntos apresentam entornos urbanos relativamente consolidados, com relativa proximidade de oferta de bens e serviços públicos e privados, bem como sistemas de transportes coletivos de razoável qualidade. No entanto, a partir dessa distância, essas condições favoráveis diminuem bastante. Tal fato sinaliza uma precariedade maior para as habitações construídas nessas faixas, especialmente as localizadas nos setores Leste e Norte e que se tratam de conjuntos destinados a famílias de mais baixa renda (Faixa 1). Para esta faixa de renda, os subsídios são maiores, mas a liberdade de escolha de localização é menor.

\section{b. Relação entre a produção local de Unidades Habitacionais do MCMV e a oferta local (por bairro) de oportunidades de trabalho formal}

Esta relação se apresentou de maneira quase inversa, mas não linear, conforme mostra a figura 3. De forma clara, se observa que o percentual da produção de unidades habitacionais (eixo $\mathrm{x}$ ) foi bem mais intensa em setores de baixa oferta local de empregos formais (eixo y), o que reforça e corrobora que tal critério, em função do preço da terra, foi bastante utilizado para a escolha das áreas de implantação, com prejuízos claros para a população moradora.

No entanto, embora não se tenha os valores exatos das oportunidades de trabalho informal, percebese que em tais áreas, tais atividades são bem 


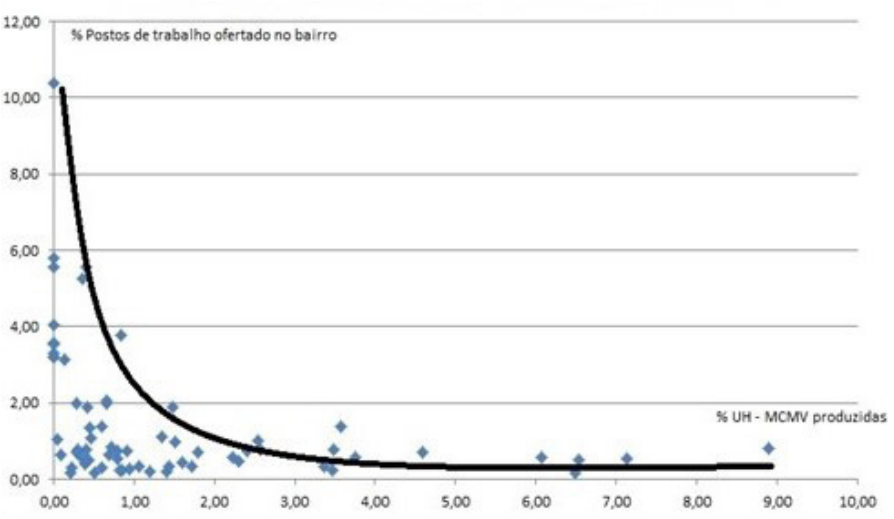

Fig. 3. Relação entre o percentual de UH produzidas por bairro e o percentual de postos de trabalho ofertados por distrito, no município de São Paulo/SP (adaptado de GI-SNH, 2018; PMSP, 2018).

presentes, com uma diversidade considerável de atividades, embora em grande parte, caracterizado pela precariedade das relações de trabalho e de certa fragilidade econômica que traduz também em certa fragilidade da qualidade de vida de seus moradores.

Outro fator que teve a capacidade de reduzir a precariedade dos bairros mais remotos onde foram implantados conjuntos habitacionais do Programa MCMV é a sua condição de proximidade com centros secundários no próprio município ou mesmo centros de outros municípios vizinhos.

\section{c. Relação existente entre o percentual de implantação de unidades habitacionais do MCMV e o índice local de violência urbana}

Para esse estudo, foi utilizado o índice clássico de violência urbana (taxa de homicídios/100 mil habitantes), adotado pela OMS e pelos Órgãos nacionais e internacionais de segurança pública. Os resultados demonstraram que, apesar da presença constante e numerosa de unidades habitacionais construídas em bairros considerados com altos índices de violência urbana, essa relação não se observou, apresentando dados bem dispersos, como pode ser observado na figura 4.

Apesar da alta concentração da violência em alguns bairros do setor sul e do setor norte, algumas áreas centrais e do setor oeste, com pouca construção habitacional no Programa apresentaram índices altos. O perfil característico da criminalidade na cidade (predominância de roubo de automóveis e assalto a bancos) faz apresentar altos índices também em áreas mais valiosas do ponto de vista imobiliário e, portanto, com pouca implantação de conjuntos MCMV. Ao mesmo tempo, o setor Leste, embora com o distanciamento da área central e dos setores geradores de emprego, se constitui um setor de grande quantidade de trabalhadores do comércio, serviços, construção civil e outras atividades de baixa remuneração, no entanto, são setores com poucas áreas de altos índices de criminalidade. Tais fatos explicam a dispersão verificada na figura abaixo.

Se, por um lado, observou-se grande produção habitacional em bairros que apresentam índices altos no contexto urbano, como Jardim Ângela (15,68 homicídios/100 mil habitantes - observado em 2011) que recebeu 606 unidades habitacionais e Campo Limpo (16,93 homicídios/100 mil habitantes) que recebeu 208 unidades, por outro lado, os bairros de Itaquera, São Miguel Paulista e Itaim Paulista, com índices de violência próximos da metade do bairro citado, receberam em média, mais que cinco vezes mais unidades habitacionais que os bairros mais violentos citados, ou seja: 3.124, 564 e 1.320 unidades habitacionais respectivamente.

Mas o caso mais emblemático dessa "não correspondência" entre índice de violência e construção de empreendimentos, notadamente no MCMV Faixa 1 foi o de Cidade Tiradentes, localizada a mais de $30 \mathrm{~km}$ do centro tradicional, com a mais

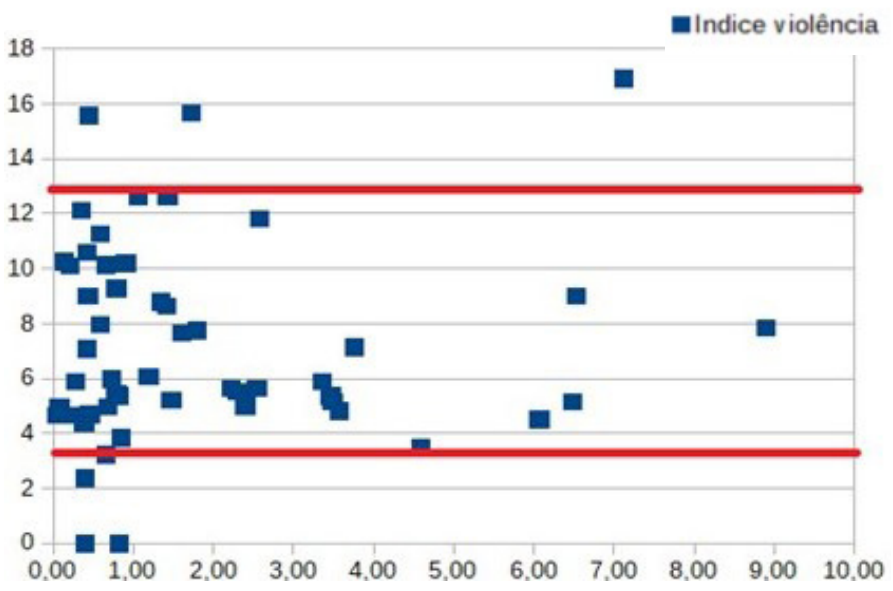

Fig. 4. (Não) relação entre o índice de violência (homicídios/100 mil habitantes) e o percentual de produção de unidades habitacionais no MCMV por distrito no Município de São Paulo (adaptado de GI-SNH, 2018; PMSP, 2018). 
alta concentração de empreendimentos apenas do MCMV faixa 1 (2.278 unidades habitacionais) e índice de violência menor do que a média do município: 5,17 homicídios/100 mil habitantes.

Dessa maneira, a conjectura da relação direta entre o índice de violência do bairro, fator que reduziria o valor da terra, e o percentual de produção de unidades habitacionais não se verificou. Notadamente no caso das faixas 2 e 3 , onde existe a possibilidade de escolha do local pelo futuro morador, esse fator seria considerado um fator de repulsão, reduzindo sensivelmente o valor da unidade habitacional, o que não agradaria os incorporadores dessas faixas. Apenas em casos onde, apesar dos altos índices de violência, o bairro estaria mais bem localizado em relação às oportunidades ou bairros considerados melhores, como o caso de Campo Limpo (16,93 homicídios/100 mil habitantes), foram observados índices mais elevados de implantação de unidades habitacionais de imóveis na faixa 2 e 3 . Sua proximidade em relação a bairros de mais alta renda (como o Morumbi) e áreas geradoras de emprego (Berrini) explica, em parte, esse comportamento excepcional. A figura 4 mostra essa dispersão e, ao mesmo tempo, uma predominância de localização das UH produzidas em áreas com índices médios de violência.

Apesar de que, na pesquisa sobre percepção social da violência elaborada pela Rede Nossa São Paulo/lbope inteligência (2019), a região Leste foi a que mais percebe um aumento da violência (81\% acham que a violência aumentou), os demais indicadores demonstram índices altos, como ocorre no país, mas moderados na comparação com outras cidades ou outras regiões da própria cidade. Na mesma pesquisa citada, observou-se que também o morador da zona Leste ainda é o que menos teme sair ou andar a pé durante a noite ou transportar dinheiro com medo da violência.

\section{d. A percepção da qualidade de vida pelos moradores nos diferentes setores da cidade}

Tomando-se como base os resultados da pesquisa Rede Nossa São Paulo-Ibope Inteligência (2019), que abrange moradores de todas as regiões da cidade verificou-se que os da região Norte foram os que mais atribuíram a nota máxima (satisfação total) à qualidade de vida na cidade (17\%), seguido dos setores Leste, Sul e Centro. Em relação à nota mínima (insatisfação total), observou-se que os menores índices de insatisfação ocorreram no Centro (1\%) e Região Leste (3\%). As maiores notas predominantes foram 8 (Região Norte e Oeste) e 7 (Região Sul e Leste).

Quando se avaliou os índices de satisfação por classe social (segundo a denominação econômica do IBGE), verificou-se que as classes $D$ e $E$ foram as que mais atribuíram a nota máxima de satisfação (23\%), embora também fossem as que mais atribuíram a nota mínima (17\%). Para essas classes de renda (que coincidem com as faixas do MCMV, notadamente a faixa 1), a nota predominante foi 8.

Para a classe de renda C o índice máximo de satisfação foi declarado por $13 \%$ e predominou a nota 07 e o índice para a insatisfação total foi de 3\%. Para as classes A e B o índice máximo foi declarado por $10 \%$ dos entrevistados e também predominou a nota 07 . Os que atribuíram a nota mínima foram 5\% dos entrevistados.

Embora a pesquisa adotada como referência para a percepção da qualidade de vida não tenha o recorte exato da população estudada, a adoção dos dois critérios simultaneamente (setor da cidade e faixa de renda) apresenta uma aproximação aceitável para a avaliação. Os resultados apresentados demonstram que, apesar da distância e da alta concentração de unidades de habitação de baixa renda, as regiões Leste, Norte e Sul mostraram índices de satisfação bastante próximos das demais regiões e até mais positivos nos setores de baixa renda, coincidentes com o perfil dos beneficiários do Programa MCMV.

\section{Considerações finais}

Ficou corroborada a prevalência do critério preço da terra e, portanto da preferência, por parte dos construtores (no caso da faixa 1 do MCMV) e dos incorporadores (no caso da faixa 2 e 3 do MCMV) da aquisição de terrenos em áreas mais distantes 
dos centros tradicionais e geradores de maior oferta de oportunidades de trabalho e renda bem como geradores de maior oferta de bens e serviços públicos e privados, em virtude do fator do custo da terra.

No entanto, verificou-se que, em função da própria dinâmica urbana, as faixas de distância onde se localiza a maior parte da implantação de unidades habitacionais do MCMV (10 a 20 km) (à exceção da faixa 1 que atinge distâncias ainda maiores em virtude da impossibilidade de escolha por parte do futuro morador), são atualmente áreas urbanas relativamente bem consolidadas, ofertando relativamente boa condição de acessibilidades a oportunidades, bens e serviços.

O maior problema ocorre nas áreas situadas a distâncias maiores que $20 \mathrm{~km}$, onde predominam os empreendimentos da faixa de renda 1 , apresentando situações bastante diferentes entre si, variando em função da sua articulação com os centros secundários, a proximidade de centros de municípios vizinhos e da acessibilidade a rede de transporte coletivo, notadamente o transporte urbano ferroviário, capaz de atender grandes distâncias em um tempo de viagem mais aceitável. Além da maior disponibilidade de solo urbano plano e da alta concentração populacional, o que contribui para a diversidade de oferta de serviços e oportunidades, a melhor acessibilidade ao transporte público, notadamente o transporte ferroviário, foi um dos fatores que levaram o setor leste da cidade a ser o predominante na implantação de empreendimentos do MCMV.

Esse problema ainda se torna mais grave no caso do MCMV faixa 1, que conforme demonstrado, são mais frequentes ainda a distâncias superiores a 20 $\mathrm{km}$ das áreas de grande oferta de oportunidades e, por se localizarem mais frequentemente em áreas menos consolidadas, apresentam também menor oferta local de oportunidades, bens e serviços. Apenas em casos em que centros secundários ou centros de outros municípios vizinhos estejam próximos, devido à conurbação, tais áreas podem apresentar melhor condição habitacional.

No que diz respeito ao impacto de dispersão urbana e na contiguidade urbana no município de São Paulo, observou-se ainda que, apesar das distâncias em relação ao centro, a produção habitacional ocorreu dentro de áreas urbanas consolidadas, utilizando-se dos próprios vazios urbanos existentes. Além da própria condição de município central e, em grande parte, conturbado com outras áreas urbanas, outros fatores contribuíram para tal inserção: a) a utilização da verticalização e habitações multifamiliares em substituição às modalidades anteriores das casas unifamiliares; b) O próprio aperfeiçoamento gradativo dos normativos do MCMV ao longo do tempo, que veio exigindo inserção urbana, melhor condição infraestrutural e outras melhorias qualitativas. Dessa maneira, conclui-se que o impacto negativo sobre a estrutura urbana, no caso específico do município foi pouco clara, inclusive com alguns aspectos até positivos como o adensamento com a ocupação de lotes vazios. No entanto, como ocorreu em várias outras regiões metropolitanas, a dispersão do tecido urbano ocorreu especialmente pela transposição para os municípios periféricos, em um descolamento territorial indesejável da oferta em relação à real demanda habitacional.

Ficou evidente também a quase ausência de empreendimentos do Programa em áreas mais centrais (apenas 0,35\% das UH no centro tradicional e nenhuma UH do programa nos chamados centros novos), mesmo em uma cidade com alguma experiência anterior neste tipo de ação. Tal informação evidencia o equívoco de não se considerar outras modalidades, tais como a requalificação de edifícios deteriorados em áreas urbanas ou periurbana próxima. Tais soluções têm sido pouco consideradas pelas políticas estatais pelo seu alto investimento inicial. No entanto, têm sido relegadas as vantagens decorrentes dessa Iocalização para os moradores e para a cidade: a) aumento de oportunidades; b) ganho de tempo extra, anteriormente perdido em deslocamentos; c) redução dos fluxos de circulação motorizada intraurbanos; d) redução da deterioração de áreas centrais, e c) melhor qualidade de vida para o morador, com a grande oferta local de bens e serviços públicos e privados. 
Como alternativas menos onerosas que a construção para transferência da propriedade, outras modalidades poderiam ser buscadas, tais como a "Iocação social ou de aluguéis de valores moderados", inclusive com a participação privada, que poderia viabilizar soluções habitacionais para maior número de pessoas, com menores investimentos por parte do Estado. Tal solução vem sendo aplicada comumente e com muito êxito em vários países no mundo. Evidentemente, para que tais soluções venham a ser exitosas, seria imperioso adotar medidas de monitoramento e acompanhamento permanente (não congelamento, mas controle de inflexões especulativas) do valor dos aluguéis no sentido de se evitar que certa "cultura inflacionária" inviabilize um programa social de aluguéis de baixo custo em áreas centrais.

\section{Referências bibliográficas}

ANDRADE, L. S. Para além da unidade habitacional: pela moradia e pela cidade no contexto da construção da minha casa e da minha vida. Rio de Janeiro: Prourb-UFRJ / CNPa-SNH, 2015.

ATLAS MUNICIPAL. Trabalho e desenvolvimento. Cidade de São Paulo. 2017. Disponível em <atlasmunicipal.prefeitura.sp.gov.br/usuario/ Cadintermediario.aspx>. Acesso em 12 set 2019.

BAUMAN, Z. Confiança e medo na cidade. Rio de Janeiro: Jorge Zahar Ed, 2009.

BENITES SOBRINHA, M. D. P. Avaliação do Programa Minha Casa Minha Vida na Região Metropolitana de Natal - RN. Natal: UFRN/ CNPq-SNH, 2015.

BONDUKI, N. Os pioneiros da habitação social: cem anos de política pública de habitação no Brasil. São Paulo: Editora UNESP, 2014.

CAIXA Econômica Federal. Empreendimentos Minha Casa Minha Vida. Disponível em: <webp. caixa.gov.br/siurb/ao/pag/index.asp $>$. Acesso em 12 set 2019.

CARDOSO, A.L. et al. O Programa Minha Casa,
Minha Vida e seus efeitos territoriais. Rio de Janeiro: Letra Capital, 2013.

CARDOSO, A. L. Avaliação do Programa Minha Casa, Minha Vida na Região Metropolitana do Rio de Janeiro: impactos urbanos e sociais. Rio de Janeiro: IPPUR - UFRJ/ CNPq-SNH, 2015.

DUTRA, W. Z. Entre a produção habitacional estatal e as moradias precárias: uma análise da popularização da casa própria no Brasil. Revista Configurações - CICS, n. 10, ano 2012, pp. 151-164, 2012.

FERREIRA, J. S. W. Produzir casas ou construir cidades?. São Paulo: LabHab/FAUUSP, 2012.

LINKE, C. et al. Inserção urbana de habitação de interesse social: um olhar sobre a mobilidade cotidiana e o uso do solo. Brasília: IPEA - Textos para discussão, 2016.

NASCIMENTO, D. M. (org.) Programa Minha Casa, Minha Vida: Estudos avaliativos na RM de Belo Horizonte. Belo Horizonte: UFMG / CNPq - SNH, 2015.

PEQUeNO, L. R. B. Análise do Programa MCMV na Região Metropolitana de Fortaleza: Desenvolvimento institucional, inserção urbana e avaliação arquitetônica, construtiva e tecnológica. Fortaleza: UFC/ CNPq-SNH, 2015.

REDE NOSSA SÃO PAULO. Viver em São Paulo: Mobilidade. Relatório de pesquisa - Rede Nossa São Paulo/IBOPE inteligência, 2019.

REDE NOSSA SÃO PAULO. Viver em São Paulo: Segurança. Relatório de pesquisa - Rede Nossa São Paulo/IBOPE inteligência, 2019.

REDE NOSSA SÃO PAULO. Vive rem São Paulo: Qualidade de Vida. Relatório de pesquisa - Rede Nossa São Paulo/IBOPE inteligencia, 2019.

ROLNIK, R. Como produzir moradia bem localizada com recursos do programa Minha Casa, Minha 
Vida? - implementando os instrumentos do Estatuto da Cidade. Brasília: Ministério das Cidades, 2010.

SAULE JR., N. A produção do programa MCMV na Região metropolitana da Baixada Santista: impactos urbanos e ambientais dos empreendimentos. São Paulo: Instituto Polis, 2015.

SHIMBO, L. Z. Produção do PMCMV na região central do Estado de São Paulo: inserção urbana, projetos e impactos socio-econômicos. São Carlos: IAU-USP / CNPa - SNH, 2015.

SILVA, E. T. Estrutura urbana e mobilidade espacial nas metrópoles. Rio de Janeiro: Letra Capital, 2012. 